\title{
Response Analysis for Pile Subjected to Vertical Direction of Seismic Shaking
}

\author{
Chien-Yuan Chen, Ming-Jin Wu \\ National Chiayi University, Dept. of Civil and Water Resources Engineering \\ No. 300, Syufu Rd., Chiayi City 60004, Taiwan ROC \\ chienyuc@mail.ncyu.edu.tw; s1020382@mail.ncyu.edu.tw
}

\section{Extended Abstract}

Earthquakes worldwide have occurred frequently in recent years. Pile foundation is used frequently when structures are located in weak sub-layers or may suffer from lateral loadings such as earthquakes. Design of pile foundations has become more important in recent years [1-4]. Numerical simulation can reduce pile field testing costs.

This study uses the FLAC3D finite difference program [5] for pile foundation subjected to earthquake shaking analysis for understanding the seismic response of piles. A designed $3 \times 3$ pile group combined with vertical and batter piles in $2 \mathrm{D}, 3 \mathrm{D}$, and $4 \mathrm{D}$ of pile space are used for the numerical simulation analysis.

The results show that when the pile group is subjected to horizontal seismic forces, the changes of the pile space will not change the axial and skin friction stresses in piles. It shows the level of horizontal seismic forces will not cause a greater variation of skin friction force in group piles. The group piles are subjected to lower axial stresses in 2D of pile space than in 3D and 4D as the group piles are subjected to vertical seismic forces. It shows considerable group effects in piles subjected to vertical seismic forces. The pile skin friction forces change is significantly greater for the 4D pile space than in $2 \mathrm{D}$ and $3 \mathrm{D}$. The study shows that the group effect could considerably greater for piles subjected to vertical direction seismic forces than for those subjected to horizontal seismic forces.

\section{References}

[1] H. G. Poulos, "Raked piles-virtues and drawbacks," Journal of Geotechnical and Geoenvironmental Engineering, ASCE, vol. 132, pp. 795-803, 2006.

[2] N. Deng, R. Kulesza and F. Ostadan, "Seismic soil-pile group interaction analysis of a battered pile group," in Proceedings of the 4th International Conference on Earthquake Geotechnical Engineering CD-ROM," Greece, 2007, Paper No. 1733.

[3] I. Shahrour, A. Hassan and S. Mhamed, "3D elastoplastic analysis of the seismic performance of inclined micropiles," Soil Dynamics and Earthquake Engineering, vol. 42, pp. 275-291, 2012.

[4] S. Escoffier, "Experimental study of the effect of inclined pile on the seismic behavior of pile group," Computers and Geotechnics, vol. 39, pp. 1-7, 2012.

[5] Itasca Consulting Group, Inc., FLAC3D, Fast Lagrangian Analysis of Continua in 3 Dimensions, user manuals, 2005. 